\title{
BMJ Open Multilevel factors influencing contraceptive use and childbearing among adolescent girls in Bara district of Nepal: a qualitative study using the socioecological model
}

\author{
Kazutaka Sekine (D) , Nirajan Khadka, ${ }^{2}$ Rogie Royce Carandang, ${ }^{1}$ \\ Ken Ing Cherng Ong, ${ }^{1}$ Anand Tamang, ${ }^{3}$ Masamine Jimba (iD ${ }^{1}$
}

To cite: Sekine K, Khadka N, Carandang RR, et al. Multilevel factors influencing contraceptive use and childbearing among adolescent girls in Bara district of Nepal: a qualitative study using the socioecological model. BMJ Open

2021;11:e046156. doi:10.1136/ bmjopen-2020-046156

- Prepublication history and additional supplemental material for this paper are available online. To view these files, please visit the journal online (http://dx.doi.org/10.1136/ bmjopen-2020-046156)

Received 21 October 2020 Accepted 25 September 2021

D Check for updates

(c) Author(s) (or their employer(s)) 2021. Re-use permitted under CC BY-NC. No commercial re-use. See rights and permissions. Published by BMJ.

${ }^{1}$ Department of Community and Global Health, The University of Tokyo, Bunkyo-ku, Tokyo, Japan ${ }^{2}$ Public Health Action Nepal, Kathmandu, Nepal

${ }^{3}$ Center for Research on

Environment Health and

Population Activities,

Kathmandu, Nepal

Correspondence to

Dr Kazutaka Sekine;

kazutaka_sekine@hotmail.com

\section{ABSTRACT}

Objectives This study aimed to identify the multilevel factors that influence contraceptive use and childbearing decisions in Nepal and examine relationships among these factors.

Design The study drew on qualitative data collected through in-depth interviews (IDIs) and key informant interviews (KIls) and triangulated results.

Setting An urban municipality and a rural municipality in Bara district, Nepal.

Participants We recruited a total of 60 participants (e.g., 20 married adolescent girls aged 15-19, 20 husbands, 20 mothers-in-law) for IDIs and 10 (e.g., four healthcare providers, three health coordinators, three female community health volunteers) for Klls.

Results Married adolescent girls faced a range of barriers that are inter-related across different levels. Patriarchal norms and power imbalances between spouses limited their decision-making power regarding contraception. Social pressures to give birth soon after marriage drove the fear of infertility, abandonment and the stigmatisation of childless married couples, which leads to lack of women's autonomy in making decisions about family planning. Mothers-in-law and religion exerted considerable influence over couples' decisions regarding contraception. Limited access to information about the benefits and methods of family planning contributed to fear of the side effects of contraceptives and low awareness about the risks involved in adolescent pregnancy.

Conclusions The convergent results from triangulation confirm that the decision to postpone childbearing is not merely the personal choice of an individual or a couple, highlighting the importance of targeting families and communities. The study underscores the need to challenge restrictive sociocultural norms so that adolescent girls become empowered to exercise greater control over contraceptive use.

\section{INTRODUCTION}

Adolescent pregnancies and childbirths are a global concern. Each year, 21 million girls aged 15-19years old in low-income and

\section{STRENGTHS AND LIMITATIONS OF THIS STUDY}

$\Rightarrow$ This study is one of the first qualitative studies to identify the multilevel, inter-related factors that influence contraceptive use and childbearing among married adolescent girls.

$\Rightarrow$ The study drew on multiple sources to collect rich and diverse data using a convenience sample from a single district and triangulated results.

$\Rightarrow$ The comprehensive approach guided by the socioecological model allowed us to analyse a complex interplay of multilayered factors that hinder contraceptive use.

$\Rightarrow$ The study is limited in the possibility of respondents having felt inhibited to share their personal experiences candidly in the presence of an interviewer.

$\Rightarrow$ It was not possible to conduct respondent validation due to logistical constraints and lack of personal information of the respondents.

middle-income countries (LMICs) become pregnant, of which 12 million girls give birth. ${ }^{1}$ Births to adolescents of this age group account for $11 \%$ of all childbirths worldwide. ${ }^{2}$ Approximately 5.7 million pregnancies in the same population segment result in abortion. ${ }^{1}$ In LMIC, $50 \%$ of all pregnancies among girls aged 15-19years old are unintended. ${ }^{3}$ Among adolescent girls who want to avoid pregnancy, 14 million have an unmet need for modern contraception. ${ }^{1}$ Addressing this need might reduce unintended pregnancy and unplanned births by 6.2 million and 2.1 million annually, respectively. ${ }^{1}$

Global and national policies often assume that the primary reason for contraceptive nonuse among adolescent girls is their personal choice (or the choice of couples). However, several other factors also prevent them from seeking family planning services and delaying childbearing in LMIC. Researchers have 
noted a number of factors that hinder married adolescent girls from using contraceptive methods and postponing childbearing. These factors can be classified into five categories: individuals (e.g., limited knowledge, the fear of adverse side effects), ${ }^{4-8}$ interpersonal (e.g., partner's refusal to use contraceptives), ${ }^{4}{ }^{5}$ family-related (e.g., influence of mothers-in-law and sisters-in-law), ${ }^{4}$ social acceptability (e.g., community expectations to prove one's fertility) ${ }^{78}$ and service delivery-related (e.g., confidentiality and privacy issues). ${ }^{9}$ However, a shortcoming of the previous qualitative research is narrow focuses on each level without examining interactions or inter-relations across different levels. Few in-depth investigations have been conducted to promote the nuanced understanding of a complex interplay of multilayered factors that hinder contraceptive use. ${ }^{10}$ Therefore, it is necessary to identify a host of the factors that impede contraceptive use and promote early childbearing.

In Nepal, the adolescent birth rate remains high at 88 births per 1000 adolescent girls aged $15-19$ in $2016,{ }^{11}$ and this figure is the second-highest in South Asia after Bangladesh. ${ }^{12}$ A national survey showed that $17 \%$ of adolescent girls aged 15-19years old were pregnant in the same year. ${ }^{11}$ Among Nepali adolescents, pregnancy is related to a lower economic status, membership to a disadvantaged ethnic group, and unemployment. ${ }^{13}$ The prevalent practice of child marriage also contributes to the high rate of adolescent pregnancy and is associated with contraceptive non-use before the first childbirth in Nepal, ${ }^{14}$ India ${ }^{145}$ and Bangladesh. ${ }^{16}$ In a nationally representative survey, $40 \%$ of Nepali women aged 20-24years old were married before the age of $18 .{ }^{11}$ About one in two married adolescent girls aged 15-19 years give birth to her first child before turning 20, typically soon after marriage. ${ }^{11}$ Although the Nepali government and its development partners have taken efforts to improve access to family planning services and information, contraceptive use remains disproportionately low among adolescent girls. Only $15 \%$ of married adolescent girls aged 15-19 use any modern contraception; in contrast, the corresponding figure is $41 \%$ among adult women aged 20 or above. ${ }^{11}$ Therefore, this study aimed to identify the multilevel factors that influence contraceptive use and childbearing decisions in Nepal and to examine relationships among these factors.

\section{METHODS}

\section{Study setting}

We conducted this study in an urban municipality (Mahagadimai Nagarpalika composed of 12 wards) and a rural municipality (Prasauni Gaunpalika composed of seven wards) in Bara district in province 2 of Southern Nepal. The province has the highest child marriage prevalence rate $(65 \%)$ among women aged 20-24 years in 2016. ${ }^{11}$ We purposively selected these two municipalities from five urban municipalities and nine rural municipalities based on consultation with respective municipality officials. Then, we randomly selected one ward in each selected municipality.

Province 2 where Bara district is located considered as least developed region in Nepal, with the lowest human development index value. ${ }^{17}$ Gender disparity of the region in terms of education and income is the most pronounced, with the lowest gender development index value. ${ }^{17}$ The district is home to 108655 households (i.e., an average of 6.3 members per household). ${ }^{18}$ The most dominant religion is Hinduism, followed by Islam and Buddhism. The men who live in these areas were primarily farmers, labourers, and small-scale business owners or employees. Married women were mostly involved in household work and farming. Most households have electricity, but power outages are frequent. Few houses have a latrine. ${ }^{18}$ Using solid fuel such as firewood and charcoal is common. Each municipality has at least one health post where only primary healthcare services are provided.

\section{Study participants}

This study relied on multiple sources to collect rich and diverse data and triangulated results. We recruited three different groups for in-depth interviews (IDIs) to cover a wide range of perspectives of household members. The first group was adolescent girls aged 15-19years old who had been married for at least six months and were living with their husbands $(n=20)$ at the time of data collection. The second group was husbands of married adolescent girls $(n=20)$. The last group was mothers-in-law of married adolescent girls $(n=20)$. We did not match IDIs participants by family for recruitment or analysis. As a complementary method, we also conducted key informant interviews (KIIs) with those who possessed firsthand knowledge about community perceptions of and barriers to adolescent pregnancy. Participants for KIIs were healthcare providers working in a government healthcare facility $(n=4)$, health coordinators working in the district health office or municipality office $(n=3)$, and female community health volunteers (FCHVs) working in the study areas $(n=3)$. Table 1 shows the focuses of IDIs and KIIs.

In the selected two wards, we purposively recruited those who met the aforementioned inclusion criteria with the help of local research assistants (the details regarding the assistants are provided below). As sampling frames were not available in the study areas, we used convenience sampling (i.e., door-to-door visits) to recruit participants of the study. We included minors aged 15-17 years for the study as they were disproportionately underserved by family planning programmes in Nepal. Vulnerabilities that are specific to this age group may account for the lower uptake of family planning services. We did not consider birth history or contraceptive use history for recruitment.

\section{Data collection}

From 5 July 2019 to 15 July 2019, we conducted semistructured IDIs and KIIs, using topic guides. These 
Table 1 Focuses of IDls and KIIs

\begin{tabular}{|c|c|}
\hline Type of participants & Focuses of IDIs and KIls \\
\hline Married adolescent girls & $\begin{array}{l}\text { Knowledge about and access to FP information and services, perceived needs, decision-making } \\
\text { power, influences of in-laws, social and gender norms, religious beliefs, privacy and confidentiality, } \\
\text { attitude of healthcare providers, policy restrictions and political priorities. }\end{array}$ \\
\hline Husbands & $\begin{array}{l}\text { Knowledge about and access to FP information and services, perceived needs, decision-making } \\
\text { power, influences of in-laws, social and gender norms, religious beliefs, privacy and confidentiality, } \\
\text { attitude of healthcare providers, policy restrictions and political priorities. }\end{array}$ \\
\hline Mothers-in-law & $\begin{array}{l}\text { Knowledge about and access to FP information and services, perceived needs, decision-making } \\
\text { power, influences of in-laws, social and gender norms, and religious beliefs. }\end{array}$ \\
\hline $\begin{array}{l}\text { Healthcare providers/ } \\
\text { health coordinators/ } \\
\text { FCHVs }\end{array}$ & $\begin{array}{l}\text { Access to FP information and services, social and gender norms, religious beliefs, challenges in } \\
\text { providing FP services, policy restrictions, and political priorities. }\end{array}$ \\
\hline
\end{tabular}

FCHVs, female community health volunteers; FP, family planning; IDIs, in-depth interviews; KII, key informant interviews.

interviews focused on the knowledge, attitudes, beliefs, perceptions and experiences that pertain to contraceptive use and childbearing (table 1). We adopted these data collection methods as they afford great flexibility in navigating the interview and depth of exploration in qualitative research. ${ }^{19}$ We developed the topic guides based on the socioecological model (SEM),${ }^{20}$ literature reviews and the research team's field observations to include previously identified key issues. The SEM is a theoretical framework to understand the dynamic interactions and inter-relations of multilevel factors that determine health behaviours. $^{21}$ McLeroy et $a .^{20}{ }^{20}$ identified five levels of influence that are specific to health behaviours: intrapersonal factors, interpersonal factors, community factors, institutional factors and policy factors. Based on literature reviews, we developed a conceptual framework (figure 1), which was adapted from the SEM. We developed and used a separate topic guide for each group. Prior to data collection, we pretested one of the topic guides on two married adolescent girls to determine the feasibility of this strategy and refine the questions. The topic guides in English are available as an online supplemental file 1.

Five Nepali research assistants (four women and one man) collected data. They speak the local language (i.e., Bhojpuri) and are experienced in qualitative research. We trained them for three days to avoid the biases that typically interfere with the collection of qualitative data (e.g., friendliness bias, social desirability, confirmation bias, question-order bias) and to address ethical considerations. All of the assistants have a bachelor's degree in public health or sociology. They conducted individual face-to-face IDIs and KIIs in a private space chosen by the participants and at a time convenient to them. The sex of the interviewer matched the sex of the participant. The interviewers established rapport with the participants before commencing the interviews. They began the interview with general questions and moved onto more specific questions, including open-ended questions about their experiences of and perceptions about contraception. The interviews lasted for approximately onehour

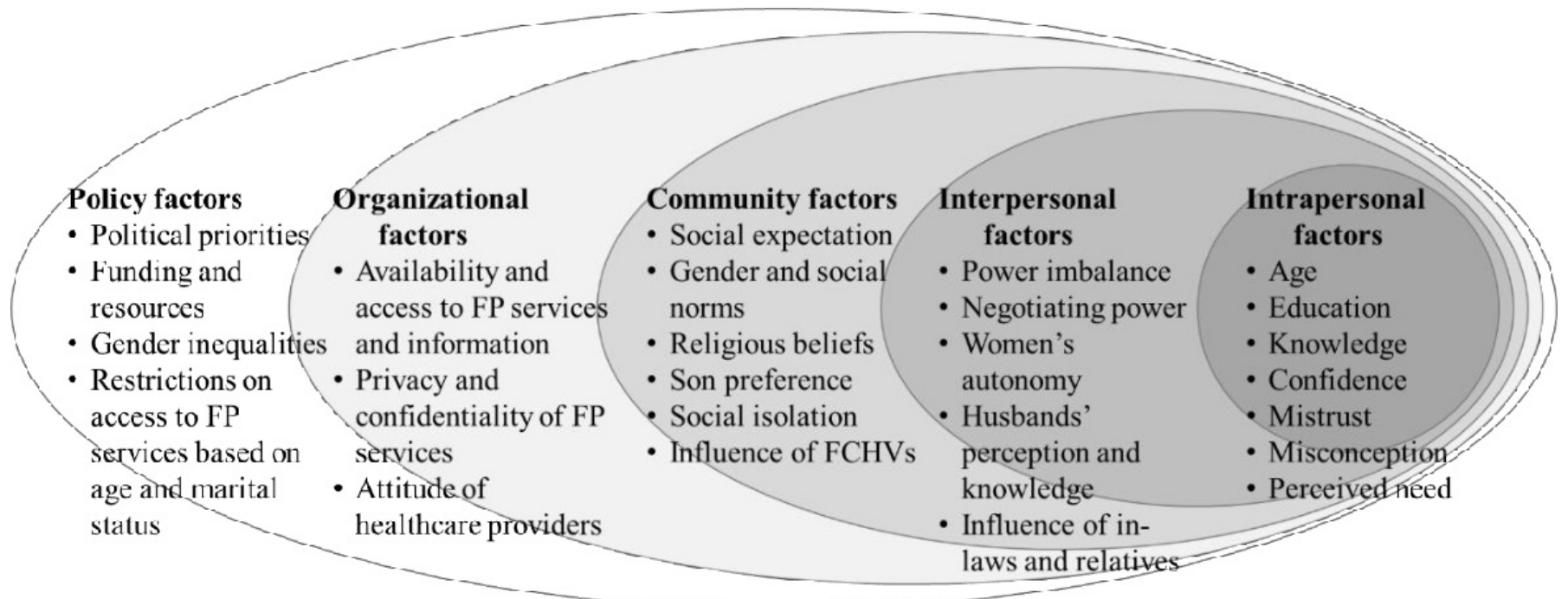

Figure 1 Conceptual framework adapted from on the socioecological model toidentify the causes of contraceptive nonuse and adolescent pregnancy. Note: adapted from McLeroy et al. ${ }^{20}$ FCHVs, female community health volunteers; FP, family planning. 
and were audiorecorded to help verify descriptive data. The interviewers transcribed verbatim both the IDIs and KIIs within 24 hours of each interview. Subsequently, the second author (NK) translated the transcribed interviews into English. The interviewers checked the translated text for errors and omissions (including context and content accuracy).

\section{Data analysis}

We analysed the data using a directed approach to content analysis, which is described by Graneheim and Lundman ${ }^{22}$ and Hsieh and Shannon, ${ }^{23}$ and in accordance with the conceptual framework. Two authors (KS and NK) read English transcripts several times to immerse into the data and gained a sense of the whole. We coded and analysed the meaning units, which were embedded within the transcripts. We also highlighted all texts, which, on the first impression, appear to represent factors influencing contraceptive use and adolescent childbearing. The next step in the analysis was to code all highlighted passages using predetermined codes based on the conceptual framework (figure 1). We gave new codes to any texts that could not be categorised with the initial coding scheme, and then reviewed and revised these codes during the entire coding process. When inconsistencies emerged, we further refined the codes through discussion until we reached consensus. We grouped emergent codes into categories, and further classified into themes in accordance with the conceptual framework: intrapersonal, interpersonal, community, organisational and policy-level factors. We translated relevant participant quotations and used them to illustrate themes. We adopted various measures to ensure that the publication of these responses does not violate the code of confidentiality. For instance, we used unique reference numbers to protect the identity of the participants. Finally, we constructed linkages among emergent categories and themes through axial coding. Respondent validation could not be conducted due to logistical constraints, and lack of personal information of the respondents. We used NVivo 9 (QSR International, Cambridge, Massachusetts, USA) to facilitate coding, organisation, searching for meaning units embedded within the English transcripts, and systematically compare the emergent categories and themes both within and across the cases. The qualitative methods and reporting of results in this study adhered to the Consolidated Criteria for Reporting Qualitative Research (COREQ ${ }^{24}$ and Standards for Reporting Qualitative Research. ${ }^{25}$ We filled and provided the COREQ as online supplemental file 2.

\section{Strategies to deal with validity threats}

We employed various strategies for establishing three types of threats to validity that are pertinent to qualitative research. ${ }^{26}$ The measures taken to reduce threats to descriptive and interpretative validity included using verbatim transcripts of the interviews, presenting participant quotations without shortening, asking open-ended questions, peer debriefing, collecting and analysing rich data, and providing the thick description of the setting, participants and themes. The research design of triangulation from a range of individuals and two data collection approaches helped handle threats to both interpretative and theoretical validity.

We secured written informed consent from the participants after they were informed about the aim, objectives and procedures of the study. For those who were younger than 18 years, we obtained written informed consent from their parents. If the parent or carer was inaccessible in the neighbourhood, we obtained it from minor participants. Participation in this study was voluntary, and the participants were free to skip interview questions or withdraw their participation at any time without penalty. They were not required to provide any personal information (e.g., name, address, phone number) during the interviews.

\section{Patient and public involvement}

Participants and the public were not involved in the study design or planning of the data analysis.

\section{RESULTS}

\section{Participant characteristics}

Table 2 summarises participants' characteristics. The mean age of the participating adolescent girls was 17.8 years (IQR 17.0-18.3). A majority of them were married before the age of 18 . Approximately half of them had at least one child, and several others were pregnant. Almost all of them had become full-time housewives living with their in-laws after marriage. All the adolescent girls had discontinued their education. The mean age of the husbands and mothers-in-law was 23.5 (IQR 21.0-25.3) and 48.4 (IQR 41.5-52.3), respectively. More than a half of the participants for IDIs were Hindu. Most of the husbands were farmers or casual labourers. The mothers-in-law had limited educational attainment. As providing the demographic characteristics of the KII participants might allow for their identification, we did not include such information in this article.

\section{Intrapersonal factors}

Fear of and misconceptions about side effects on health

Both the married adolescent girls and husbands considered their fear of the side effects of contraceptive methods to be a factor that influences their decisions about family planning. They were concerned that the use of such tools would adversely affect their physical health. They also held misconceptions about the side effects of contraceptives. The following characteristic responses illustrate this observation:

I have heard that if we use an implant, there will be a lot of bleeding. Pills will harm the body, and it will feel hot if you use them. (Ref. \#122, married adolescent girl, 18 years) 
Table 2 Demographic characteristics of the participants for in-depth interviews

\begin{tabular}{|c|c|c|c|c|c|c|c|c|}
\hline \multicolumn{3}{|c|}{ Married adolescent girls $(n=20)$} & \multicolumn{3}{|l|}{ Husbands $(n=20)$} & \multicolumn{3}{|l|}{ Mothers-in-law $(n=20)$} \\
\hline & $\mathbf{M}$ & $\mathbf{P}$ & & M & $\mathbf{P}$ & & $\mathbf{M}$ & $\mathbf{P}$ \\
\hline Age (years) & & & Age (years) & & & Age (years) & & \\
\hline $18-19$ & 9 & 5 & $20-24$ & 3 & 8 & $40-49$ & 4 & 5 \\
\hline Age at marriage (years) & & & $25-29$ & 2 & 3 & $50-59$ & 3 & 3 \\
\hline $15-17$ & 5 & 7 & & & & & & \\
\hline $18-19$ & 2 & 0 & & & & & & \\
\hline Religion & & & Religion & & & Religion & & \\
\hline Hinduism & 6 & 7 & Hinduism & 6 & 6 & Hinduism & 6 & 7 \\
\hline Muslim & 4 & 4 & Muslim & 3 & 5 & Muslim & 4 & 3 \\
\hline Terai Dalit & 1 & 5 & Terai Dalit & 5 & 4 & Terai Dalit & 2 & 3 \\
\hline Others (Teli or unknown) & 1 & 1 & & & & & & \\
\hline Educational attainment & & & Educational level & & & Educational level & & \\
\hline $\begin{array}{l}\text { No education or } \\
\text { some level of primary } \\
\text { education }\end{array}$ & 4 & 4 & $\begin{array}{l}\text { No education or some level } \\
\text { of primary education }\end{array}$ & 1 & 0 & $\begin{array}{l}\text { No education or } \\
\text { some level of primary } \\
\text { education }\end{array}$ & 9 & 10 \\
\hline $\begin{array}{l}\text { Completed primary } \\
\text { school }\end{array}$ & 1 & 3 & Completed primary school & 1 & 2 & $\begin{array}{l}\text { Completed primary } \\
\text { school }\end{array}$ & 1 & 0 \\
\hline $\begin{array}{l}\text { Some level of secondary } \\
\text { education }\end{array}$ & 2 & 3 & $\begin{array}{l}\text { Some level of secondary } \\
\text { education }\end{array}$ & 3 & 6 & & & \\
\hline Tailor & 0 & 1 & Labourer & 3 & 4 & Farmer & 3 & 6 \\
\hline No of children & & & Businessperson & 2 & 4 & Labourer & 3 & 0 \\
\hline 0 & 3 & 8 & Teacher & 0 & 1 & $\mathrm{CHV}$ & 1 & 0 \\
\hline 1 & 4 & 2 & Helper & 0 & 1 & Businessperson & 1 & 0 \\
\hline 2 & 3 & 0 & Tailor & 0 & 1 & & & \\
\hline
\end{tabular}

CHV, community health volunteer; M, Mahagadimai Nagarpalika; P, Prasauni Gaunpalika.

There is a chance of becoming infertile if contraceptives are used for a long time. (Ref. \#992, husband, 21 years) about free family planning services. (Ref. \#630, married adolescent girl, 17 years)

\section{Lack of access to information}

Several married adolescent girls were unaware that they could avail of family planning services free of charge at public healthcare facilities. All the three groups demonstrated poor knowledge about family planning services.

I think there is a need for family planning services and information. However, no one provided us with such information

\section{Shyness and embarrassment}

Most of the married adolescent girls cited shyness and embarrassment as barriers that prevented them from discussing the timing of childbearing and contraceptive use with their husbands. Both the married adolescent girls and husbands were not inclined to seek family planning information and services, especially from healthcare providers of the opposite sex. 
I will feel very shy to ask about family planning methods. It was only a year of my marriage, and they [healthcare providers] told me not to use contraceptives. If I must ask anybody about it, I will feel very shy. (Ref. \#460, married adolescent girl, 17 years)

Low awareness about the risks involved in adolescent or multiple pregnancies

Low awareness and misinformation about the risks involved in adolescent childbearing emerged as a contributor to contraceptive non-use. While only a few married adolescent girls were aware that adolescent pregnancy was associated with an increased risk of obstetric complications, several respondents had low levels of knowledge about the risk.

If a woman gives birth before 18 years of age, she will suffer from weakness, stomachache, and vomiting and will not be able to work much and always feel sleepy. (Ref. \#122, married adolescent girl, 18 years)

\section{Limited autonomy in making decisions about family planning}

The respondents were governed by strong cultural norms, which empower husbands to make all household decisions and disallow wives from making independent decisions. Such patriarchal values, wives' financial dependence, and power imbalances between spouses had restricted women's decisions about contraceptive use. A few married adolescent girls reported that their husbands had refused to use contraceptives. They also noted that defying their husband's decisions would lead to family feuds.

If I use it [contraceptives] and if I start having its side effects, then my husband will scold me. That is why he takes all the decisions. He makes major decisions because he earns and governs the family. (Ref. \#122, married adolescent girl, 18 years)

In our community, men make all decisions. I want to use contraceptives, but he does not want me to. He does not agree on the use of contraceptives. According to him, it will harm my body. (Ref. \#335, married adolescent girl, 17 years)

We [young wives] must live on another person's income to live and have to do whatever the other person says. That is why we do not have the right to make decisions. (Ref. \#460, married adolescent girl, 17 years)

\section{Interpersonal factors}

\section{Influence of mothers-in-law}

The mothers-in-law undermined their daughter-in-law's autonomy in making decisions about contraception. Most of the married adolescent girls reported that their mothers-in-law had pressurised them into not using contraceptives until they had an ideal number of children.

My mother-in-law influenced my decision. She has the right to make decisions regarding my contraception and childbearing. (Ref. \#241, married adolescent girl, 16 years)
Limited mobility

Most of the Hindu and Muslim wives considered limited mobility to be a barrier that hindered them from accessing family planning information and services as their husbands and mothers-in-law restricted their rights to travel.

If I do not take permission to go out, there is a chance of fighting with my husband. (Ref. \#241, married adolescent girl, 16 years)

Women must seek permission to go out not only from their husbands but also from their parents-in-law and other elders in the family. Only a few disobey such norms and go to a health facility for service. Exclusion and violence against women are a common consequence if they disobey family norms. (Ref. \#587, FCHV, 35 years)

\section{Community factors}

Social pressure to give birth soon after marriage and fear of infertility

Most of the married adolescent girls, husbands, and mothers-in-law cited the extreme pressures to give birth soon after marriage as a reason for contraceptive nonuse and early childbearing. The married adolescent girls noted that, if a woman does not give birth within the first three years of her marriage, others will ridicule the woman and gossip about her infertility. They feared abandonment and the stigmatisation of childless married couples. Their family and community members had intimidated them into becoming pregnant. The married adolescent girls believed that their communities expected them to deliver their first child within the first year of marriage. In contrast, most of the husbands thought their community members expected couples to have their first child between the second and fifth year of marriage.

My community believes that women should give birth in the first year of their marriage. If they do not, people will start suspecting and gossiping about their infertility. (Ref. \#29, married adolescent girl, 19 years)

If a couple does not have a child after 4-5 years of marriage, people have negative thoughts about it. They would ask, "Why doesn't she have a child?" [and] "Is she having a problem with her reproductive capacity?" If she does not have a child after 3-4 years, parents may decide to arrange another marriage for their son. (Ref. \#230, husband, 22 years)

As illustrated by the following response provided by a mother-in-law, the fear of elopement can exacerbate such social pressures.

Community members think that getting pregnant soon after marriage is good as women cannot elope with another guy if they have a child. They can better take care of their child and give birth to a healthy baby. (Ref. \#756, mother-in-law, 55 years)

Concerns about child health and development also contribute to the pressures to which women are subjected. 
They [my family] also think that giving birth soon after marriage will contribute to the early development of the baby. (Ref. \#630, married adolescent girl, 17 years)

\section{Role of religious beliefs in contraception}

Religious beliefs were a major barrier that prevented Muslim women from seeking contraceptives. However, Hindu women did not share the same perspective.

Our religion [Islam] teaches that the use of contraceptives is a sinful act. (Ref. \#930, married adolescent girl, 19 years)

In Islam, we believe that if we use contraceptives, God becomes unhappy and punishes us. (Ref. \#241, married adolescent girl, 16 years)

\section{Lack of engagement with FCHVs}

FCHVs, who are responsible for disseminating reproductive health information, conducting family planning counselling and distributing condoms and oral pills in their communities, did not actively engage married adolescent girls in family planning activities. Women's restricted mobility impeded their access to FCHVs and limited opportunities to learn about contraceptive methods.

\section{I have never met a female health volunteer since I never leave} my house. I do not think there is a discussion about this [family planning issues] in our community. (Ref. \#892, married adolescent girl, 18 years)

I know that there are mothers' group meetings regularly in this municipality, but I haven't noticed or heard that FCHVs discuss with young couples about family planning issues. (Ref. \#352, mother-in-law, 48 years)

\section{Organisational factors}

Lack of privacy and confidentiality

A few of the husbands and healthcare providers reported that concerns about confidentiality deterred married couples from visiting healthcare facilities to obtain contraceptives.

Confidentiality is not maintained in some private clinics because my single friend went to a private clinic to buy condoms, and, later, this information was spread among their professional network. (Ref. \#992, husband, 21 years)

Couples themselves do not feel comfortable with going to government health facilities owing to a lack of privacy and confidentiality. There is no separate space for family planning counseling and services in health facilities. (Ref. \#729, health care provider, 31 years)

\section{Attitudes of healthcare providers}

A few of the married adolescent girls complained about the attitudes of healthcare providers.

When seeking antenatal check-up during my pregnancy at a private clinic, the staff members were not friendly to me. They spoke only to my husband and asked him about my problem. (Ref. \#335, married adolescent girl, 17 years)
Healthcare providers reported other health systemsrelated barriers that prevented them from accessing family planning services, including (i) stockouts of contraceptives at healthcare facilities, (ii) the unavailability of female health workers who provide family planning counseling and services to female clients, and (iii) overlap between the working hours $(10 \mathrm{am}$ to $3 \mathrm{pm})$ of healthcare facilities and the time at which the housewives were busy with their household duties.

\section{Policy-level factors}

None of the participants reported policy-level factors.

\section{DISCUSSION}

This study is one of the first qualitative studies to identify the multilevel, inter-related factors that influence contraceptive use and childbearing among married adolescent girls. It extends the evidence base by illustrating the multidimensionality and interaction of the factors that limit young married women's family planning knowledge, undermine their autonomy in decision making, reduce contraceptive use, and increase the risk of adolescent pregnancy. The barriers were intertwined and influenced each other across different levels of the SEM (figure 2). The barriers were identified across the intrapersonal, interpersonal, community and organisational levels. Barriers at the intrapersonal level were reluctance to seek family planning information and services, the fear of and misconceptions about side effects of contraceptives, low awareness about the risks involved in adolescent pregnancy, a lack of access to information, and limited autonomy in making decisions about family planning. Barriers at the interpersonal level were restricted mobility, power imbalances between spouses, and mothers-in-law's influence. Barriers at the community level were the fear of infertility and abandonment, the stigmatisation of childless married couples, normative gender roles and social pressures to give birth soon after marriage, which emerged as root causes of contraceptive non-use. Barriers at the organisational level were a lack of privacy and confidentiality, and the unfriendliness of healthcare providers. The hypothetical relationships in figure 2 are depicted based on the findings from this study.

The women who participated in this study were not empowered to make independent decisions about contraception. Their husbands and mothers-in-law were deeply involved in this decision-making process. Adolescent married girls, their husbands and mothers-in-law keenly felt the pressure to bear a child within the first few years of marriage. None of the participating husbands and in-laws supported the idea of delaying the first pregnancy. Disapproval of contraceptive use before having an ideal number of children in the family was prevalent among them. Newly married adolescent girls had often become pregnant before they were ready to fulfil familial expectations to bear a child and prove their fertility. Patriarchal norms and power imbalances between spouses made 


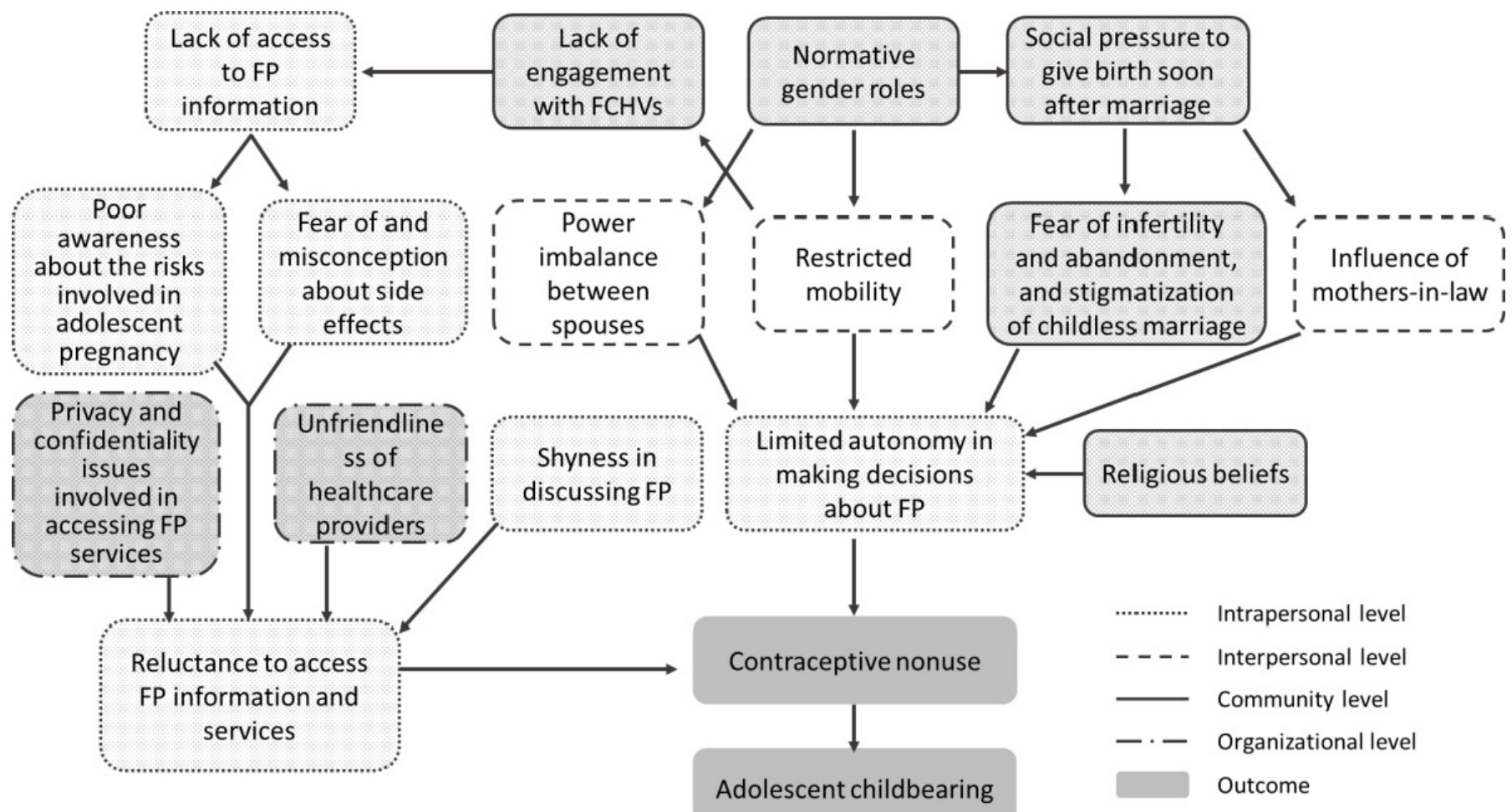

Figure 2 A diagram of hypothetical relationships among the emergent factors. Note: There was no relevant findings on policylevel factors. FCHVs, female community health volunteers; FP, family planning.

married adolescent girls hesitate or refrain from talking to their husbands about family planning and limited their decision-making power regarding contraception. The present findings corroborate with previous studies that have found social pressures to give birth soon after marriage in India, ${ }^{46}$ Bangladesh ${ }^{78}$ and $\operatorname{Iran}^{27}$ and limited autonomy in making decisions about family planning in Nepal, ${ }^{10}$ Bangladesh ${ }^{7}$ and $\operatorname{Iran}^{27}$ and among Syrian refugees in Lebanon. ${ }^{5}$

The married adolescent girls felt insecure, presumably because newly married women were not considered a valuable member of their in-law's family until they prove their fertility. Similar to the findings of previous studies in Iran ${ }^{27}$ and Bangladesh, ${ }^{8}$ delivering a healthy child soon after marriage was perceived as a means to establishing her identity and consolidating her position within her husband's family. Additionally, labour migration to India, Malaysia and the Middle East was common in the study areas. As such, having a child may be perceived as a way to cement the bond between a husband and his wife before his departure. ${ }^{8}$

Married adolescent girls' views on family planning were shaped by their mothers-in-law. They exerted considerable influence over couples' decisions regarding contraception as they were perceived as the most experienced household member in relation to family planning. Their pressure on daughters-in-law to prove fertility within the first few years of marriage was identified as a strong driver of contraceptive non-use. Given the restricted mobility of married adolescent girls, mothers-in-law and sistersin-law were their primary sources of information about contraception. Similar results regarding the influence of mothers-in-law have been reported in Nepal, ${ }^{10}$ Bangla$\operatorname{desh}^{7}$ and Lao People's Democratic Republic. ${ }^{9}$

Social pressures to give birth soon after marriage, normative gender roles and religious beliefs emerged as the root causes of contraceptive non-use. Social pressures to have a child soon after marriage drove the fear of infertility, abandonment and the stigmatisation of childless married couples, which impeded the married adolescent girls' access to family planning services. Mothers-in-law may amplify the social pressure to have a child soon after marriage. Normative gender roles were linked to restricted mobility among married adolescent girls. Furthermore, religious beliefs substantially limited their autonomy in making decisions about contraceptive use. This finding of religious restrictions is in agreement with a previous study in Bangladesh. ${ }^{7}$ In contrast, in another study conducted in Syria, religious beliefs did not emerge as a barrier to reproductive decisions. ${ }^{28}$

Limited access to information about the benefits and methods of family planning had multiple intrapersonallevel effects. It contributed to fear of and misconception about the side effects of contraceptives. It also led to low awareness about the risks involved in adolescent pregnancy. Some married adolescent girls were unaware of free family planning services provided at government healthcare facilities. Fear of the side effects has been recognised as a barrier to contraceptive use in India, ${ }^{4}$ Bangladesh ${ }^{7829}$ and Iran. ${ }^{27}$ Dropping out of school may have limited their opportunities to learn about sexual and reproductive health issues and to expand their social 
networks. The findings of this study support existing evidence that shyness in discussing family planning with husbands and healthcare providers impedes access to family planning services in Asian countries. ${ }^{49} 90$

In addition to the intrapersonal-level factors, supplyside barriers (e.g., a lack of privacy and confidentiality, the unfriendliness of healthcare providers) may have rendered them reluctant to seek contraceptives. Issues related to commodity insecurity, distance and transport did not seem to influence contraceptives-seeking behaviours in this study. Health systems-level factors (e.g., a lack of privacy and confidentiality, the unfriendliness of healthcare providers) have been found to be contributing factors for contraceptive non-use among married adolescent girls in Lao People's Democratic Republic. ${ }^{9}$

The convergent results from triangulation across multiple sources (i.e., six different groups) and two data collection methods painted a complex and comprehensive portrait of the barriers to contraceptive use and causes of adolescent childbearing. However, the findings should be interpreted within the confines of several limitations of this study. First, a convenience sample was recruited from a single district in Nepal. Therefore, the findings may not be transferable to broader populations. Second, the participants may have felt inhibited to share their personal experiences candidly, especially those that pertain to sensitive subjects, in the presence of an interviewer. For example, they may have felt uncomfortable reporting other prevalent, although extremely stigmatised experiences (e.g., abuse and neglect) that influence contraceptive use. In this study, efforts were made to obtain in-depth data by interviewing in a private space, establishing rapport with the participants, and maintaining confidentiality. Third, due to lack of respondent validation, the possibility of misinterpreting the meaning of what the respondent said could not be ruled out. Fourth, the relationships shown in figure 2 are intended to be an illustrative set of relationships, rather than an exhaustive set. Minor linkages are not necessarily reflected in the diagram. Finally, the meanings embedded within participants' responses might have been lost or distorted during translation from Nepali to English. To minimise this problem, the interviewers checked the accuracy of the translated texts for errors and omissions. Despite these limitations, the strengths of this study include its comprehensive approach guided by the SEM, triangulation across multiple sources and methods, which enabled the collection of rich and detailed data, and other strategies for establishing validity.

\section{CONCLUSIONS AND PROGRAMMATIC IMPLICATIONS}

The present findings delineate the mechanism of contraceptive non-use and adolescent pregnancy in the study setting. In-depth accounts of a range of individuals demonstrated that the decision to postpone childbearing is not merely the personal choice of an individual or a couple, highlighting the importance of targeting families and communities in addition to adolescent girls and couples. Expanding access to comprehensive sexuality education to enhance girls' knowledge and demand for sexual and reproductive health may not be enough to prevent adolescent pregnancy. Instead, the present findings underscore the need to challenge restrictive sociocultural norms so that adolescent girls become empowered to exercise greater control over contraceptive use. Community support and collective actions are needed to address the root causes that have been identified in this study. Men and boys must be engaged to challenge and transform gender norms and stereotypes relating to childbearing and family planning and to address negative effects that these norms and stereotypes can have on women, girls, family and communities. Reproductive health programmes and interventions should be culturally sensitive and context-specific and aim to reinforce women's reproductive rights and gender equality. Adopting human rights-based approaches to adolescent sexual and reproductive health is essential to ensure women's autonomy in exercising their reproductive rights by determining when to have a child and how many children to have.

Acknowledgements The authors would like to express our gratitude to the participants for their valuable contribution to the qualitative research in Bara district, Nepal. The first author acknowledges the Foundation for Advanced Studies on International Development for financially supporting him while pursuing a Ph.D.

Contributors KS conceived and designed the study, analysed the data and wrote the draft manuscript. NK jointly analysed the data. NK, RRC, KICO, AT and MJ contributed to the interpretation of the results and made critical suggestions for revisions to the manuscript. MJ supervised the study. KS is responsible for the overall content as guarantor. All authors read and approved the final manuscript.

Funding This study was part of the first author's doctoral dissertation and was financially supported by the Foundation for Advanced Studies on International Development (2017-2018).

Competing interests None declared.

Patient consent for publication Consent obtained from parent(s)/guardian(s)

Ethics approval The present study was approved by the Research Ethics Committee of the Graduate School of Medicine, the University of Tokyo (2019030NI), and the Nepal Health Research Council (3001) in Kathmandu.

Provenance and peer review Not commissioned; externally peer reviewed.

Data availability statement Data are available on reasonable request. The data generated during the current study are not publicly available due to restrictions (e.g., their containing information that could compromise the privacy of research participants) but are available from the corresponding author on reasonable request.

Supplemental material This content has been supplied by the author(s). It has not been vetted by BMJ Publishing Group Limited (BMJ) and may not have been peer-reviewed. Any opinions or recommendations discussed are solely those of the author(s) and are not endorsed by BMJ. BMJ disclaims all liability and responsibility arising from any reliance placed on the content. Where the content includes any translated material, BMJ does not warrant the accuracy and reliability of the translations (including but not limited to local regulations, clinical guidelines, terminology, drug names and drug dosages), and is not responsible for any error and/or omissions arising from translation and adaptation or otherwise.

Open access This is an open access article distributed in accordance with the Creative Commons Attribution Non Commercial (CC BY-NC 4.0) license, which permits others to distribute, remix, adapt, build upon this work non-commercially, and license their derivative works on different terms, provided the original work is properly cited, appropriate credit is given, any changes made indicated, and the use is non-commercial. See: http://creativecommons.org/licenses/by-nc/4.0/. 


\section{ORCID iDs}

Kazutaka Sekine http://orcid.org/0000-0003-2413-2027

Masamine Jimba http://orcid.org/0000-0001-5659-3237

\section{REFERENCES}

1 Guttmacher Institute. Investing in Adolescents' Sexual and Reproductive Health in Low- and Middle-Income Countries. New York: Guttmacher Institute, 2020.

2 World Health Organization (WHO). Why is giving special attention to adolescents important for achieving millennium development goal 5? Geneva: WHO, 2008. https://www.who.int/maternal_child_ adolescent/events/2008/mdg5/adolescent_preg.pdf?ua=1

3 Sully E, Biddlecom A, Darroch JE. Adding it up: investing in sexual and reproductive health 2019. New York: Guttmacher Institute, 2020.

4 Ghule M, Raj A, Palaye P, et al. Barriers to use contraceptive methods among rural young married couples in Maharashtra, India: qualitative findings. Asian J Res Soc Sci Humanit 2015;5:18-33.

5 Cherri Z, Gil Cuesta J, Rodriguez-Llanes JM, et al. Early marriage and barriers to contraception among Syrian refugee women in Lebanon: a qualitative study. Int J Environ Res Public Health 2017;14:836.

6 McClendon KA, McDougal L, Ayyaluru S, et al. Intersections of girl child marriage and family planning beliefs and use: qualitative findings from Ethiopia and India. Cult Health Sex 2018;20:799-814.

7 Shahabuddin ASM, Nöstlinger C, Delvaux T, et al. What influences adolescent girls' decision-making regarding contraceptive methods use and childbearing? A qualitative exploratory study in Rangpur district, Bangladesh. PLoS One 2016;11:e0157664.

8 Henry EG, Lehnertz NB, Alam A, et al. Sociocultural factors perpetuating the practices of early marriage and childbirth in Sylhet district, Bangladesh. Int Health 2015;7:212-7.

9 Sychareun V, Vongxay V, Houaboun S, et al. Determinants of adolescent pregnancy and access to reproductive and sexual health services for married and unmarried adolescents in rural Lao PDR: a qualitative study. BMC Pregnancy Childbirth 2018;18:219.

10 Maharjan B, Rishal P, Svanemyr J. Factors influencing the use of reproductive health care services among married adolescent girls in Dang district, Nepal: a qualitative study. BMC Pregnancy Childbirth 2019;19:152.

11 Ministry of Health (Nepal), New ERA, Micro International Inc. Nepal demographic and health survey 2016. Kathmandu, Nepal: Ministry of Health, Nepal, 2017

12 United Nations Department of Economic and Social Affairs. World fertility 2019. New York, 2020. Available: https://www.un.org/en/ development/desa/population/publications/pdf/fertility/World Fertility_2019.pdf

13 Poudel S, Upadhaya N, Khatri RB, et al. Trends and factors associated with pregnancies among adolescent women in Nepal: pooled analysis of Nepal demographic and health surveys (2006, 2011 and 2016). PLoS One 2018;13:e0202107.

14 Godha D, Hotchkiss DR, Gage AJ. Association between child marriage and reproductive health outcomes and service utilization: a multi-country study from South Asia. J Adolesc Health 2013:52:552-8.

15 Raj A, Saggurti N, Balaiah D, et al. Prevalence of child marriage and its effect on fertility and fertility-control outcomes of young women in India: a cross-sectional, observational study. Lancet 2009;373:1883-9.

16 Kamal SMM. Decline in child marriage and changes in its effect on reproductive outcomes in Bangladesh. J Health Popul Nutr 2012;30:317-30.

17 Khanal DR, Pandey PR, Sharma B. Nepal human development report 2020. Kathmandu, Nepal: Government of Nepal and United Nations Development Programme, 2020.

18 Central Bureau of Statistics (Nepal). National population and housing census 2011. Kathmandu, Nepal: Central Bureau of Statistics, 2012.

19 Marshall C, Rossman GB. Designing qualitative research. Thousand Oaks: SAGE Publications, 2016.

20 McLeroy KR, Bibeau D, Steckler A, et al. An ecological perspective on health promotion programs. Health Educ Q 1988;15:351-77.

21 Sallis JF, Owen N, Fisher EB. Ecological models of health behavior. In: Glanz K, Rimer BK, Viswanath K, eds. Health behavior and health education: theory, research, and practice. xxxiii. San Francisco, CA, US: Jossey-Bass, 2008pp.: 465-85.

22 Graneheim UH, Lundman B. Qualitative content analysis in nursing research: concepts, procedures and measures to achieve trustworthiness. Nurse Educ Today 2004;24:105-12.

23 Hsieh H-F, Shannon SE. Three approaches to qualitative content analysis. Qual Health Res 2005;15:1277-88.

24 Tong A, Sainsbury P, Craig J. Consolidated criteria for reporting qualitative research (COREQ): a 32-item checklist for interviews and focus groups. Int J Qual Health Care 2007;19:349-57.

25 O'Brien BC, Harris IB, Beckman TJ, et al. Standards for reporting qualitative research: a synthesis of recommendations. Acad Med 2014;89:1245-51.

26 Maxwell JA. A realist approach to qualitative research. Thousand Oaks: SAGE Publications, 2012: 585-6.

27 Mardi A, Ebadi A, Shahbazi S, et al. Factors influencing the use of contraceptives through the lens of teenage women: a qualitative study in Iran. BMC Public Health 2018;18:202.

28 Hessini L, Abortion HL. Abortion and Islam: policies and practice in the middle East and North Africa. Reprod Health Matters 2007:15:75-84.

29 Schuler SR, Bates LM, Islam F, et al. The timing of marriage and childbearing among rural families in Bangladesh: choosing between competing risks. Soc Sci Med 2006;62:2826-37.

30 Barua A, Kurz K. Reproductive health-seeking by married adolescent girls in Maharashtra, India. Reprod Health Matters 2001;9:53-62. 